\title{
Internet applications, sites, trends and happenings
}

\author{
David Raitt \\ draitt@estec.esa.nl
}

This column aims to draw your attention to various interesting Web sites that the author has come across and that might appeal to you. You will be kept up to date with news and views on Web trends and developments. Essentially it offers a personal selection rather than comprehensive coverage.

\section{Happy hunting ground for Web sites}

Where do old Web sites go when they die or otherwise become defunct? With any luck, they will end up in the Internet Archive - a non-profit project which aims at preserving the history of the Web. The archive (http://Web.archive.org) has been going for some five years and has just launched the Wayback Machine - type in any URL and you can see what it looked like in the good old days (well, at least as far back as 1996). The Wayback Machine is claimed to be the largest database in the world with more than 10 billion pages. The archive allows you to see sites that are no longer operational (it is hard to erase pages once they are on the Web), trace how pages have evolved over time with different graphics and styles, and follow past events on the Web.

The Internet Archive is a public non-profit organization that was founded to build an 'Internet library' with the purpose of offering permanent access to researchers, historians and scholars to historical collections that exist in digital format. Founded in 1996 and located in the Presidio of San Francisco, the archive has been receiving data donations from Alexa Internet and others. In late 1999, the organization started to build more well-rounded collections.

Libraries exist to preserve society's cultural artifacts and to provide access to them. If libraries are to continue to foster education and scholarship in this era of digital technology, it is essential that they extend those functions into the digital world. Without cultural artifacts, civilization has no memory and no mechanism to learn from its successes and failures. The Internet Archive is working to prevent the Internet, a new medium with major historical significance, and other 'born-digital' material from disappearing into the past. Collaborating with institutions, including the Library of Congress and the Smithsonian, the Internet Archive is working to permanently preserve a record of public material.

\section{Web trends and statistics}

The city of Pittsburgh has the fastest growing on-line population of any city in the US, reports CyberAtlas (http://cyberatlas.internet.com/big_picture/geographics/article/0,5911_961051,00.html).

According to data from Nielsen/NetRatings (http://www.nielsen-netratings.com/), the online population in the city jumped 20,4\% from December 2000 to December 2001, giving Pittsburgh an on-line population of about 1,2 million. Olympic host Salt Lake City took 
second place as its Internet population grew with $20 \%$ to 973000 surfers, while the surfing population of Phoenix jumped 17\% to 1,4 million. The Internet population of Raleigh, N.C. grew 13,4\% over the year, reaching 821000 surfers. Rounding off the top five fastest growing wired cities, Philadelphia posted a 12,8\% increase to nearly 3,1 million Internet surfers. The rest of the top 10 fastest growing wired cities were Cleveland, Minneapolis, Los Angeles, Kansas City and Detroit.

There is evidence that the big jump in Pittsburgh's on-line population could be partly attributable to its teenagers. A study by Digital Marketing Services, Inc. for America Online found that Pittsburgh is the top wired city for teens in the United States, based on time spent on-line. The survey of more than 6700 parents of teens and teens (aged 12-17) found that Pittsburgh teens are on-line an average of 15,82 hours per week. The nationwide average is 12,28 hours per week.

In another interesting story found on NUA Internet surveys (http://www.nua.ie/surveys/), English is losing dominance on the Web. Global Reach has released its latest statistics on the use of languages on-line (http://www.glreach.com/globstats/index.php3), and at the end of 2001 only $43 \%$ of the global on-line population were native English speakers. Thirty-two per cent were native speakers of European languages and 24,7\% had an Asian language as their mother tongue.

After English speakers, the next biggest language group is Japanese speakers, who comprise $8,9 \%$ of the world's Internet users, followed by Chinese (8,8\%), German $(6,8 \%)$, Spanish $(6,5 \%)$, and Korean $(4,6 \%)$ speakers. Italian is the mother tongue of $3,8 \%$ of all users, while French is the native language of $3,3 \%$.

In a news item under NUA's African survey, it appears that the nomadic nature of many South African Internet users has sparked a boom in the use of free Web-based e-mail services. Two idiosyncrasies of South African Internet users have driven the trend. Among younger users, the nomadic nature of their academic and job environments encourages use of easily accessed e-mail. International business travel among a large proportion of older users is also underpinning the growth of free-mail services. Among the better-known freemail providers, Hotmail and Yahoo! compete actively in the South African market with Webmail and Ananzi Mail, as well as with lesser-known services like Myiafrica.com.

Industry analyst Arthur Goldstuck conducted the research on behalf of independent consultancy World Wide Worx. According to the survey, more than half a million free Web-based e-mail accounts are in active use in South Africa. Goldstuck notes that the popularity of free Web-based e-mail services represents a churn threat to existing ISPs, who have not fully persuaded South Africans of the value of their offerings relative to the cost of their services. By maintaining Web-based mail accounts, users are able to hop from one access service to another without concern about contacts keeping track of their addresses.

\section{The universe on the Net}

The Internet is now bringing its users the whole world on-line. Astronomers from 17 research institutions have announced that they are starting an ambitious new project to put the universe on-line. The National Virtual Observatory (NVO), headed by astronomer Alex Szalay of The Johns Hopkins University and computer scientist Paul Messina of the California Institute of Technology, will unite astronomical databases of many earthbound and orbital observatories, taking advantage of the latest computer technology, and data storage and analysis techniques. The goal is to maximize the potential for new scientific insights from the data by making them available in an accessible, seamlessly unified form to professional researchers, amateur astronomers and students. 
The new project is funded by a five-year, $\$ 10$ million information technology research grant from the National Science Foundation. Organizers characterize their goal as 'building the framework' for the National Virtual Observatory. Szalay, the Alumni Centennial Professor of Astronomy in Johns Hopkins' Krieger School of Arts and Sciences, views the NVO as a significant step forward in formalizing a third major approach to scientific research that has been growing in usefulness and popularity in recent years. Advances in technology and technique now double the total amount of information astronomers annually gather from observatories. 'If ways to distill information and insights from these floods of data are not developed, then astronomers will end up like shipwrecked sailors on a desert island, surrounded by an ocean of salt water and unable to slake their thirst', co-principal investigator Messina says.

The NVO was inspired by the Digital Sky Project (http://www.npaci.edu/envision/v15.3/digitalsky.html), an NSF-funded project that works to make data from four different astronomy databases available through one seamless Web portal. The NVO will take some of its basic techniques from an earlier multi-disciplinary, multi-institutional NSF-funded project that developed different and improved methods for accessing and analysing large volumes of scientific data.

A key challenge for the NVO will be developing ways to simultaneously analyse data from several of the dozens of astronomical databases available today. Each of those databases is organized differently, which makes it quite difficult to perform analyses of data from several collections simultaneously. Those kinds of investigations promise to yield important scientific discoveries, so the NVO will work to streamline the ability to do such analyses. Computationally, NVO will do this work through a set of approaches and techniques known as 'grid' computing. Grid computing was developed in the 1990s and enables scientists in multiple institutions to easily and rapidly share data and other problem-solving resources. Astronomy has actually been at the forefront of archiving and sharing data electronically for at least two decades. Organizers are planning to keep the NVO 'virtual' (not located in any one facility) and accessible enough for non-specialists like science teachers or students to use. More information on the National Virtual Observatory is available at the project Web site http://us-vo.org.

\section{Information maps for business decisions}

The central problem that WebMap solves for business professionals and managers is that business decisions must frequently be based on enormous amounts of data. To convert this data into useful information, processing must take place according to various parameters. A map is a proven way to locate data, show patterns and discover relationships, particularly when the data are large and may involve complex parameters.

WebMap enhances a company's ability to make realtime, strategic business decisions by using innovative information mapping technology. Just as weather maps summarize immense quantities of information to help us understand present conditions and to forecast the immediate future, information maps offer the potential to improve the management of a business. WebMap provides visual information mapping technology software with the ability to connect, aggregate and filter large quantities of complex data in realtime and then present the data in an information map to:

- Highlight patterns and trends;

- represent business opportunities and threats;

- provide fast and easy communication of relevant information and its significance to managers, business professionals and knowledge workers; and

- enable managers and business professionals to act on strategic information before 
opportunity windows narrow and close.

In an age of information overload, WebMap helps the user determine what information is important and helps the user to understand it, use it and profit by it. The technology TotalVIEW enables a user to find, aggregate and process enormous quantities of distributed data by presenting it in the form of an information map. An information map effectively and quickly communicates patterns and trends and is very similar to a geographical map in that it summarizes and conveys the essence of an enormous amount of information. It presents information pictorially, providing it with context and meaning so that users can understand it and make use of it to some benefit.

Humans have used maps for thousands of years to focus activity, set direction and successfully navigate toward objectives. Recognizing the superior capability of a map to quickly communicate large quantities of complex information to people, WebMap applies the concept of mapping to information as used by knowledge workers to make business decisions. The WebMap software makes it easy to transform large collections of data with all the parameters and associated attributes into a representative, interactive map, enabling data locations, patterns, trends and relationships (representing opportunities or threats to your business) to be shown clearly. The mapping software includes the capabilities for data connectivity, information processing and visual presentation.

Visit the WebMap site at http://www.Webmap.com/ for a demo to see how the software works or to download the software to zoom the Web yourself.

\section{Tegrity WebLearner studios in Texan classrooms}

Tegrity Inc. recently announced that El Centro College, located in Dallas, Texas, has significantly expanded its on-line content creation and technology-enhanced teaching capabilities with the purchase of an additional 24 Tegrity WebLearner Studios. The new Tegrity products and services (totaling approximately $\$ 375,000$ ) were purchased using funds from three grants and programme start-up funding: the first a Title III grant for strengthening institutions in inner city areas, the second a Telecommunications Infrastructure Fund (TIF) grant for technology infrastructure and the third a TIF grant for distance education in health occupations programmes.

Lisa Theriot, Executive Director of Resource Development at El Centro, says: 'We were looking for ways to infuse technology into instruction and significantly expand our abilities to better serve students on-line and in the classroom. Tegrity takes us from having "very little" to being able to make an impact across the entire institution in a very short time.'

The Tegrity WebLearner platform enabled El Centro to address these goals with one integrated platform that includes multiple functions. The 24 new WebLearner Studios joined the two 'pilot' systems El Centro already owns. Over 30 faculty members are now lined up to put them to use according to their individual needs, as well as adding multimedia and media-rich content creation capabilities to mathematics and English labs. Most portable cart-based WebLearner Studios will be stationary in classrooms, with four available for checkout. The mobile travel case-based system will be utilized for home-host instruction on other campuses in the Dallas County Community College District, as well as presentations at Allied Health professional meetings.

The systems that were funded through a TIF grant must be dedicated to connecting people through a viable and sustainable telecommunications infrastructure for schools, libraries, health care facilities and higher education institutions. The technology must demonstrate a quality, practical impact. This impact will be realized at El Centro through its Nursing and 
Allied Health programme. Director Kathy Moriarty will be developing on-line courses beginning with the Invasive Cardiovascular Technician Technology curriculum, one of only two accredited programmes in the state of Texas. There is a critical need to provide better training to health care workers throughout Texas, and El Centro College plans to provide more accessibility to learning through on-line access.

The Tegrity WebLearner platform will enable El Centro College to automatically convert classroom instruction into engaging and effective content and deliver it on-line over any Internet connection. They plan to create streaming lectures and software tutorials for distance learning courses and on-campus learning, and to provide access for students at multiple bandwidths. The platform includes the patented WebLearner Studio's server software, client software, and optional hosting and streaming service.

Theriot adds: 'Tegrity WebLearner should help us improve learning for our inner city youth, especially in our developmental studies program where it is important to offer different learning modalities to students. Many students are visual learners and need more than just text to learn.'

The Title III Grant coordinator, Harriet Crews, was looking for a way to expand the school's multimedia capabilities with limited physical space available. The campus had already gained international attention for making use of a nine-story, turn-of-the-century department store, renovated to accommodate classrooms, laboratories, computer technology, a student centre, learning centre and administrative offices, as well as labs, arts facilities, a gymnasium and library. 'We were full and couldn't add another room in our fixed space', said Crews, 'but we found a creative way to solve our space issues with Tegrity WebLearner Studios, which can convert any classroom into a technology-enhanced classroom with minimal effort'.

Additional information about Tegrity can be found at http://www.tegrity.com or by calling +1-800-411-0579.

\section{Internet commerce revolutionizing business and consumer practices}

The Internet is fast becoming an indispensable tool for businesses and consumers. Consumers can now buy, sell and trade commodities from virtually anywhere. As Internet commerce increases, greater demands are placed upon the technology needed to manage this commerce, provide efficient customer service and ensure secure transactions. Robert Bignall, a leading expert in the field of Internet commerce technologies and author of a new book entitled Internet Commerce and Software Agents: Cases, Technologies and Opportunities, shares his expertise in the following interview.

Q. What opportunities has the Internet provided for businesses?

A. The Internet has created tremendous business opportunities and is revolutionizing the whole structure of retail merchandising and shopping. Internet usage around the world is said to be doubling every ten days. The number of people on the Internet is expected to increase ten fold from around 100 million in 1999 to one billion by 2005.

Q. What is the biggest transformation on the Internet?

A. The biggest transformation resulting from this is in the area of Internet commerce, which is enabling participating businesses to simultaneously serve both domestic and foreign customers, even from the first day of their operation. There are many examples demonstrating that organizations can reap benefits, if they can innovate successfully, using Internet commerce. Consequently, marketers may spend large sums to create and promote on-line brands. 
Q. What is the future of Internet commerce?

A. According to an April 2000 Forrester research report, the rush for customer acquisition will swell the on-line promotions market to $\$ 14$ billion by 2005. So there is no doubt that it will be imperative for businesses to be part of the global Internet commerce community. With the development of Internet trading, the amount of business information available on the Internet is growing at an extraordinary speed. Management, security, legal and other issues are arising accordingly. Existing businesses are seeking answers to the question of if and how they can adapt their business processes to meet new demands and new startups that are arising to take advantage of the shifting strategic horizons of Internet commerce.

Q. What implications does the growth of Internet commerce have for customers and merchants?

A. As the Internet grows, it is becoming unfeasible for customers and merchants to manually visit each Web site, analyse the information there and thus make sound business decisions regarding the trading of goods or services. Under such circumstances it is inevitable that buyers may miss finding the best deal in the vast ocean of information. In this scenario the use of software agent technologies, both mobile and stationary, offers a new paradigm for trading on the Internet and presents a revolutionary approach to conducting analysis and market research.

Q. How can software agents be used to enhance these processes?

A. Software agents may be designed to be capable of automating routine, tedious and timeconsuming tasks involved in today's trading processes. They may be able to negotiate and make autonomous decisions and commitments on behalf of their owners. With knowledge about the habits and shopping trends of the e-consumers, accurate and personalized user profiles may be created. Agent technologies may use this knowledge to establish a much higher degree of sales confidence and create loyal and sustained relationships with customers. However, software agents for Internet commerce still have some way to go before they can fully demonstrate all of their potential advantages and ensure participant trust with regard to their privacy and the security of the transactions they undertake.

Q. What are some of the most pressing topics for discussion regarding the Internet's effect on commerce?

A. Topics include the development of intelligent tools, business models to maximize the benefits of agent technologies, agent-based payments, recommended systems, Web-based smart card agents, Internet lottery systems and wireless virtual communities.

Q. What are some of the problems and concerns of building a Web-enabled enterprise? A. One concern is the need for an improved understanding of Internet commerce. This can be obtained through an overview as well as some requirements, benchmarks, development and implementation methodologies, and approaches to successfully achieve the ultimate goal of producing robust, effective and viable Web-enabled enterprise information systems. Another important consideration is the impact of Internet commerce on export marketing strategies. The main determinants of an electronic export marketing strategy need to be examined. How firms can best capitalize on Internet commerce for their particular types of products and services is also an important discussion. A first attempt to incorporate new technologies into existing theory on export entry strategy, as well as providing a basis to conduct future research to measure the effects of Internet commerce on export performance, is one step in the right direction.

Q. How do consumers seem to react to the rise in Internet commerce opportunities?

A. The issues of consumer trust and confidence in Internet commerce are fundamental to its eventual success. If consumers cannot be confident that personal information is safe and secure, the Internet will never reach its economic potential. There is therefore a very strong 
incentive for the Internet business community to provide a safe and acceptable business environment for consumers. Policymakers need to recognize the inherent complexity and unique dynamics of the global Internet mass market in the 21st century.

Q. How does knowledge management theory and practice fit into all of this?

A. A socio-technical perspective on intelligent agents argues that the new business environment requires a reconceptualization of knowledge management. Therefore, the infrastructure and technological functionality needed to support knowledge management will be an important topic of future research. A proposed framework is based on the data life-cycle and on knowledge discovery by using intelligent agents. One of the key ideas is that in this period of profound social and economic changes, managers should focus on the meaning of information, not on the technology that collects it.

Q. How are agents affecting e-commerce?

A. Agents can facilitate the various activities necessary for successful e-commerce. Different types of intelligent agents are currently being utilized in different e-commerce models and markets. A generic architecture for designing and implementing such agents is important.

Q. What is a typical conceptual framework for designing and developing software agents? A. A conceptual framework for designing and developing software agents that will enable customized electronic commerce, as well as several effective techniques for building specific constructs within this framework, should be discussed. Some of the key characteristics of customized electronic commerce are demonstrated by experimentally prototyped software agents. Examples are electronic tour agents, electronic property agents and electronic auction agents. Technical feasibility is demonstrated based on available market products and existing research findings. Some of the key challenges in turning agent research into commercial applications are presented with an overview of electronic commerce business models and a discussion of how they can benefit from the new developments in agent technologies. Examples of the work that is being undertaken include projects from the IST research programmer of the European Union.

Q. What is a secure agent fabrication, evolution and roaming?

A. A secure agent fabrication, evolution and roaming (SAFER) architecture for agent-based e-commerce provides services for agents in e-commerce and establishes a rich set of mechanisms to manage and secure them. The three main aspects of the SAFER architecture are agent fabrication, agent evolution and agent roaming.

Q. What are some of the main concerns of e-commerce implementation?

A. The issues of usability, security and mobility are major concerns for e-commerce implementations that aim to gain widespread public acceptance. There are some who propose a combination of software agents and smart cards to build a smart card agent environment. A functional overview and design of the proposed environment illustrate how these two technologies can be integrated to offer e-commerce services with high usability, security and mobility. A prototype implementation of the concept has demonstrated how the various agents can work with a smart card agent in a secured way.

Q. What impact does or will customer service have on e-commerce?

A. It may be argued that high quality, personalized customer service will be one of the more significant drivers of e-commerce success. Therefore, a more human visual interface to the Web will be an important step towards making agent technology more accessible and userfriendly to on-line consumers. One example is a prototype 3-D audio-visual virtual salesperson. Such an interface has the potential to automatically generate a voice response to any of the routine natural language queries received by organizations from customers. 
Q. What about payment mechanisms over the Internet?

A. Internet-based payment mechanisms are an integral part of Internet commerce. Payment systems have evolved from metal coins, paper notes and bank checks to savings cards credit cards, and now electronic forms through an abstract representation of commodity values.

Development of secure payment systems over an open network is a basic prerequisite to the success of on-line commerce. There are e-payment schemes designed for agent-based SAFER e-commerce. Incorporating cryptographic techniques with software agent technology, the scheme aims to provide a flexible and secure financial infrastructure for Internet commerce.

Q. What other aspects of Internet-based payments are currently being discussed?

A. A new payment mechanism is proposed for the use of software tools on demand, which charges users according to how much they have used a given tool. This amounts to pay-peruse rental.

Q. Why is it important for professionals, both business and technology orientated, to become educated in emerging Internet technologies?

A. Professionals from the business community need to improve their understanding of the technical concepts involved in present and future Internet commerce, if they are to participate in the emerging global market place. Technologists need to achieve a better understanding of the trading applications to which Internet technology and software agents may be applied.

Robert Bignall is Pro Vice-Chancellor of Monash University, Malaysia. In his new book Internet Commerce and Software Agents: Cases, Technologies and Opportunities he addresses the timely issues of Internet commerce and provides practical guidance and useful case studies for business people, academicians and practitioners alike. The book is available from Idea Group Publishing, Hershey, PA, USA (420 pages, Copyright 2001, ISBN: 1930708-01-7), http://www.idea-group.com or 1-800-345-4335.

Internet marketing research key to success in e-commerce As more and more dotcom companies are failing, many investors in e-commerce technologies are searching for the key to success. Many believe that succeeding in business on the Web begins with effective and targeted marketing efforts. Ook Lee, a leading expert in the field of Internet marketing research and author of a new book entitled Internet Marketing Research: Theory and Practice shares his insight in the following interview.

Q. Why is effective marketing important for organizations doing business on the Internet? A. Internet marketing has become an important issue for many businesses around the world with any form of commercial presence on the Net. It is often perceived that doing business on the Internet mostly requires competency in the technology area. However, as many dotcom companies are failing due to lack of revenue generation, which could be the result of inadequate marketing and marketing research, practitioners and scholars of e-commerce are keen to obtain a better understanding of the whole phenomenon of Internet marketing. To understand what is working as an Internet marketing strategy or tactic, one needs to conduct marketing research using rigorous statistical methodology.

Q. What are some of the important tools for conducting Internet marketing research? A. A comparative analysis of Internet marketing companies with real-life company profiles is useful. Also, an explanation of the technology used in the collection of on-line consumers' information and on how on-line information can be utilized by the Internet marketing context is important to the discussion. Another important area is the marketing of e-books. Some suggest that there could be various pricing tactics to prevent cannibalization of printed books. 
Q. Why is rigorous statistical analysis important when conducting marketing research on the Internet?

A. Rigorous statistical analysis is important to find out what is working as a marketing tactic. For example, one researcher analysed 122 UK companies to find out which factors influence marketing performance on the Web. Another conducted correspondence analysis of 15 telecom companies with Web presence to obtain an objective evaluation technique of Web sites. Some other researchers utilized regression analysis of questionnaires of 98 subjects to identify motivations for the use of commercial Web sites. A very extensive statistical analysis was completed to investigate the interaction effects between the search strategy of software agents and the consumer's product class knowledge.

Q. What does the future hold for Internet marketing research?

A. Some authors suggest that instead of Porter's four Ps, we should adopt four Is (intensity, integration, interaction and identification) for the fundamental marketing mix of Internet marketing. Another author suggests that we should apply household production theory to explain the causes of consumers' willingness to contribute to Internet Web sites, including buying and selling. Some other researchers are investigating the theory behind the role of leverage and the strategic alignment of organizations while creating new markets in Internet marketing and e-commerce.

Q. What are the practical issues surrounding Internet marketing research?

A. A detailed tour of currently available Web advertisement measurement techniques provides a framework for better metrics of Web advertisement effectiveness. Also, overviews of the current research comparing consumer purchase behaviour on the Internet and in brick-and-mortar stores are useful. Many researchers focus on getting a look at what goes on in the mind of a consumer while surfing the Net, including emotions such as satisfaction, frustration and delight.

Q. Who is interested in Internet marketing research?

A. Internet marketing research can provide lots of useful information and insight, not only to academics but also practitioners, since knowledge obtained through this kind of research usually represents the statistically significant sample of the real population. Therefore, research on this area should continue by collaboration between industry and academics for the purpose of acquiring and sharing valuable consumer data.

Ook Lee is a Professor in the Department of Management at the University of Nevada, Las Vegas, USA. In his new book Internet Marketing Research: Theory and Practice, he addresses the issues of marketing on the Internet and the current trends in research. The book is available from Idea Group Publishing, Hershey, PA, USA (272 pages, Copyright 2001, ISBN: 1-287289-97-7) or http://www.idea-group.com or 1-800-345-4335.

\section{Disclaimer}

Articles published in SAJIM are the opinions of the authors and do not necessarily reflect the opinion of the Editor, Board, Publisher, Webmaster or the Rand Afrikaans University. The user hereby waives any claim he/she/they may have or acquire against the publisher, its suppliers, licensees and sub licensees and indemnifies all said persons from any claims, lawsuits, proceedings, costs, special, incidental, consequential or indirect damages, including damages for loss of profits, loss of business or downtime arising out of or relating to the user's use of the Website. 
SSN 1560-683X

Published by InterWord Communications for the Centre for Research in Web-based Applications, Rand Afrikaans University 